\title{
Rape and Other Forms of Violence Among Women Who Have Sex With Women In Tanzania: A 'New' Public Health Concern?
}

\author{
Saidah M. Bakar ${ }^{1}$, Jackline V. Mbishi², Happiness P. Saronga ${ }^{3}$, \\ and Switbert R. Kamazima ${ }^{3 *}$
}

${ }^{1}$ Community Health Department, School of Public Health and Social Sciences, Muhimbili University of Health and Allied Sciences, P.O. Box 65001 Dar-es-salaam, Tanzania.

${ }^{2}$ Epidemiology and Biostatistics Department, School of Public Health and Social Sciences, Muhimbili University of Health and Allied Sciences, P.O. Box 65001 Dar-es-salaam, Tanzania.

\author{
${ }^{3}$ Behavioral Sciences Department, School of Public Health and Social Sciences, \\ Muhimbili University of Health and Allied Sciences, \\ P.O. Box 65001 Dar-es-salaam, Tanzania.
}

\begin{abstract}
Female same sex behaviors and practices are considered a taboo, immoral, and illegal in many societies around the globe. In many countries and some societies, same-sex relationships are a crime punishable to several years in prison, life imprisonment or death. Women who have sex with women, therefore, face almost all forms of violence whose consequences to the women's health and wellbeing in these countries and societies remain a neglected public health concern. We conducted a cross-sectional descriptive and retrospective qualitative formative study among WSW in Ilala, Kinondoni and Ubungo, districts of Dar-es-Salaam City region, Tanzania. The field study was conducted between January and February, 2021. One of the objectives was to understand from the women who have sex with women's perspectives, their lived experiences with rape and other forms of violence to inform public health intervention programs so that available healthcare resources can be used to respond to women who have sex with omen's needs arising from diverse forms of violence experience. Results demonstrate that rape is women who have sex with women's daily lived experience in this country. These women presented they are stigmatized and discriminated by their immediate family members,
\end{abstract}

community members and leaders, employers, and law reinforcement machinery. We recommend awareness creation through diversity training to all levels: families, communities, law enforcement machinery, (public) healthcare personnel as a strategy to improve women who have sex with women's quality of life and care that would facilitate preventing and controlling illnesses among this at risk and expanding group in this country.

Keywords: women who have sex with women, female same sex violence, rape, qualitative research, Tanzania.

\section{Introduction}

Female same sex relationships, behaviors and practices are considered a taboo, immoral, and illegal in many societies around the globe. In many countries and some societies, same-sex relationships are a crime punishable to several years in prison, life imprisonment or death. Women who have sex with women (WSW), therefore, face almost all forms of violence (abuse, rape, rejection, discrimination, criminalization, intimate partner violence). Female adolescents engaging in same-sex sex are vulnerable to bullying and family rejection. Sexual minority stress, which is a response to stigmatization, 
prejudice, and internalized homophobia, contributes to many of these conditions [1]. The number of same sex among young adults (18-24 years) is higher compared to different sex counterpart [2]. Romero, et al. [3], reports that LGBTQ+, youths are left homeless especially in the situation like covid pandemic due to family rejection and their providers if same sex being discriminated. The Centers for Disease Control and Prevention (CDC) found that $44 \%$ of lesbian women and $61 \%$ of bisexual women have experienced rape, physical violence or stalking by a partner, compared to $35 \%$ of straight women [4]. WSW's and lesbians' rape by men as a measure to cure their lesbianism or "corrective rape" is on the rise in different parts of the world and on the African continent in particular [5].

The en.wikipedia.org adds,

Corrective rape is reported to be on the rise in South Africa. The South African nonprofit "Luleki Sizwe" estimates that more than 10 lesbians are raped or gangraped on a weekly basis. As made public by the Triangle Project in 2008, at least 500 lesbians become victims of corrective rape every year and $86 \%$ of black lesbians in the Western Cape live in fear of being sexually assaulted. Victims of corrective rape are less likely to report the crime because of their society's negative beliefs about homosexuality [6].

Reporting on South Africa, Turley [7], for example, reports,

NoxoloNogwaza, a South African lesbian and LGBTI rights activist, was raped and murdered in April 2011 ... Eudy Simelane, a lesbian who played for South Africa's national soccer team and was the first open lesbian in her township, was repeatedly raped before being stabbed and thrown naked into a nearby drainage ditch in 2008 ... Nineteen-year-old ZoliswaNkonyana was stoned and stabbed to death in 2006, just steps from her home in the township of Khayelitsha ... The list goes on!

Since 2008, mob attacks targeting LGBT and healthcare workers serving the LGBT community have been ongoing along the Kenyan Coast [8]. The situation is more or less similar in Tanzania. According to the Executive Director, LGBT Voice Tanzania (2009),

Homophobia against LGBT individuals and activists in Tanzania is well known. The challenges vary from everyday personal hardships to high-level factors such as hostility from civil society organizations, religious bodies, government, and law

\section{ISSN 2455-6378}

enforcement. In many cases, homophobia is perpetuated by policies that criminalize Homosexuality or neglect our basic human rights. Harassment, rejection, and violence lead many of us to actively hide our feelings and relationships, denying ourselves the social support that could improve our health and quality of life. As people come to know LGBT people and have better information about us, we may achieve common understanding that LGBT people are interested in the same rights and privileges as others in our society [9].

In Ouma's [9] view, "The root causes of homophobia against LGBT are many and varied. Lack of knowledge about homosexuality is an important factor, leading to misperceptions and fear of promotion of homosexuality." In addition, October 2018, the then Dar-es-Salaam Regional Commissioner (RC) announced establishing a 17member surveillance squad comprised of state officials from the Tanzania Communications Authority, the police and media practitioners that was expected "to begin to get their hands on them [homosexuals][from the then] next Monday" [10].

We are in the dark about the extent of violence against women in same-sex relationships in Africa and in Tanzania in particular. It is from this background that we conducted a qualitative formative study, among other objectives, to understand from the WSW's perspectives, their lived experiences with violence, stigma and discrimination to inform public health intervention programs so that available healthcare resources can be used to respond to WSW's needs arising from diverse forms of violence experienced.

\section{Materials and methods}

The Muhimbili University of Health and Allied Sciences (MUHAS) Institutional Review Board (IRB) reviewed and granted clearance to our study protocol on female same sex behaviors and practices in Dar-es-Salaam Region, Tanzania. We conducted field study between January and February, 2021. The study was conducted in three districts: Ilala, Kinondoni and Ubungo, whose Administrative Secretaries (DAS) granted permission to collect data needed in their respective areas. The Village/Street authorities, managers of I/NGOs/institutions caring for LGBT granted permission to conduct the study in their respective areas and institutions.

We used four methods to collect data needed: indepth interviews (IDIs) with WSW, proxy WSW, 
female same-sex relationships potential women and girls and community members; focus group discussions (FGDs) with WSW and members of community; observations of female same sex relationship-related issues throughout our stay in the study area and we collected WSW's life stories.

Our study participants included adults aged 18 years or older who could legally consent. The process of interviewing neither had harm to nor re-traumatized the study participants. The average duration of the interviews and FGDs was one and half hours. However, as our participants had interest in this study, some IDIs and FGDs took longer time, up to two hours. The aim was to understand, from the study participants' perspectives, WSW's experiences with abuse, violence, rape, rejection, criminalization and discrimination in Tanzania. FGDs and IDIs were conducted in Kiswahili, a national language understood by almost everybody in the study area. We transcribed and translated data, followed by data analysis applying thematic approach where open systematic coding of data in the participants' language and combining emerging emic concepts with preconceived theoretical constructs was used.

\section{Results}

We asked our study participants a question: What are the daily life experiences of WSW in this country? We further probed on the general public's and the families' reactions to female same sex behaviors and practices, WSW's experience with rape, stigma, rejection and discrimination, and WSW's experiences with the law enforcement machinery, particularly with the police.

\subsection{General perceptions}

Explaining daily life experience, a participant aged 28 , never married, a female sex work (FSW) with Olevel education, running a males' salon and playing a female role in same sex relationship, reported,

I live and enjoy my life like other citizens I dress and present myself as a woman ... No one could suspect me practicing same sex None of my family members has an idea of my sexual behaviors ... However, the tomboys, the transmen and transwomen, face challenges from the community ... Some of them are raped, beaten and stigmatized ... Some are evacuated from houses or rooms they rent ... Some face discrimination at workplaces, at home and at worshiping places (IDI, E, 28 years, 2021).

Another participant aged 29, never married and exclusively having sex with women, stated, "Some
ISSN 2455-6378

of our colleagues are well educated with qualifications and some hold positions in the public or private sectors ... However, others never get employed due to their sexual orientations ... Whenever they do get such opportunities, they are required to dress like females, which pushes them off' (IDI, D, 29 years, 2021).

\subsection{Public's/community reactions towards WSW}

Discussing how the community treats the WSW, a participant aged 35, divorced, a female sex worker and started engaging in same sex at the age of 19 , explained as follows,

"You know, we [WSW] are the same as other women in this country and our daily life is similar to that of straight women ... However, the problem arises when community members recognize that you are engaging in same sex behaviors and practices ... They bull you when walking on the streets ... For example, I comfortably lived in Magomeni [Kinondoni district] area for about five years ... When the landlord and neighbors knew I engage in same sex they started pointing a figure at me ... The youth and adults in that street looked in a manner that devalue me ... Some would directly confront me threatening to beat or rape me ... It reached a point I couldn't handle such harassments ... I decided moving to Sinza [Kinondoni district]" (IDI, B, 35 years, 2021).

Another participant aged 46, never married, a mother of two children, identifying a tomboy [male] and started engaging in same sex at the age of 19, reported,

Our society is divided with regard to us [WSW] ranging from those who accept us, those who tolerate us to those who criminalize us ... Majority of community members do not accept our sexual behaviors and practices ... They wonder why should women engage in same sex ... They believe we are cursed ... They have no idea that we were created to be who we are and what we want to be ... It [same sex] is common and accepted in Europe, Uganda and South Africa ... In Dar [Dar-es-Salaam] there are places like Kinondoni, Oyster Bay, Masaki and Magomeni where same sex behaviors and practices are common and are either accepted or tolerated ... Not in Mbagala, Tandika [Temeke district] and other similar areas of the [Dar-esSalaam] city where same sex is still considers a taboo and immoral ... In those areas people will ridicule you, gossip about you at every corner you pass ... In fact, you will be treated in a mockery way ...Y You know, same sex, be it women having sex with women or SMS, is 
illegal in Tanzania ... It [same sex] is a criminal offence in our country(IDI, G, 46 years, 2021).

Discussing how the public perceives WSW, a participant aged 26, a transman and a university graduate reported, "Almost all religious leaders are against our behaviors and practices ... They believe [same sex] is devilish and bad luck to our families ...Majority say we should get fiancés and then marry and nurture our [nuclear] families" (IDI, F, 26 years, 2021).

Reporting on WSW's evacuation from houses or rooms they rent due to their sexual orientations, participant aged 46 , never married, a mother of two children and has sex with men, stated,

As I told you, I am living with my family, so I have no such experience ... However, I know my friends [WSW] who have been chased out of the house they rented when the land-lords knew they were lesbians ... You know, when they rent a house or rooms, they are accepted as sisters or a mother and her daughter ... As days pass on, they demonstrate lesbian-like behaviors which, irritate the landlords and the neighbors leading to their evacuation ... However, there are some of them who are living amicably with their landlords and the neighbors (IDI, G, 46 years, 2021).

\subsection{Family reactions(discrimination)}

The participants were asked if their families knew that they engage in same sex. A participant aged 32, never married, mother of one kid and has sex with men, for example, reported, "None of my family members know I engage in same sex practices" (IDI, B, 35 years, 2021). Another participant aged 46, never married, a mother of two children and has sex with men, reported, "Aaaaah, [laughter] ... None of my family members knows that I engage in same sex ... All they know is that I enjoy having male's company ... So, even if I 'import' [bring a female partner at home] they can't be suspicious and no one would come to my room to check what is going on between us ... So, I am safe that way" (IDI, G, 46 years, 2021). A Street Leader interviewed in Kinondoni observed, "Yes, when some parents learn their child is a lesbian, they become angry and may reject that child even expel or chase her from their homes" (IDI, K, 60 years, 2021).

\subsection{Rape experiences}

We probed if participants have ever experienced rape. One participant said, "Personally, I have never experienced rape although, I have ever been

\section{ISSN 2455-6378}

threatened to be raped... However, it happened to my closest friend.” Adding,

My friend [name] a straight girl went out with her friends [a group of three] who were in this business [same sex] ... Apparently, the three women were longing to have affairs with her for a long time ... They took her to a club in Sinza [name] where they bought drinks and "nyamachoma" [barbeque] until she was overdosed [overdrunk] ... They took her to their ghetto and raped her ... They even took videos of that event ... When she gained consciousness, she enquired what happened to her ... They told her that 'you were so drunk ... we had to undress you so that you get fresh air ... She could not recognize she had been raped ... After a week or so, another woman approached her asking for sexual relation or for intimacy ... She resisted saying she is not used to same sex practices ... and the woman who wanted to be intimate with her showed her the video recorded the day she was raped ... She cried a lot ... However, she is now used to it [same sex] ... She switches roles: a tomboy [male], a bottom [female] and a FSW (IDI, B, 35 years, 2021).

Regarding rape experiences among WSW, a participant aged 26, a transman and a university graduate reported, "I have never experienced rape harassments ... However, I know one tomboy [transman] who was recently raped by a gang of men who claimed punishing her for her same sex behaviors and practices ... They call it ... I don't know, correct rape" (IDI, F, 26 years, 2021). Another participant aged 46, never married, a mother of two children and has sex with men, said, "I have never been raped or rape a woman ... I have no experience with rape among us [WSW] ... However, I have heard such cases of a man raping a kid or a woman on a TV [television] and radio" (IDI, G, 46 years, 2021).

\subsection{Experiences with stigma, rejection and discrimination.}

A participant aged 32, never married, mother of one kid and has sex with men, reported, "Stigmatization exists among community members ... Once they recognize you are a lesbian or a sex worker you can't be elected a member of the Street Committees" (IDI, H, 32 years, 2021). A participant aged 35, divorced and a FSW reported, "It happened that I was evacuated in the house I rented in Sinza three years ago because the landlord recognized I am a lesbian 
and a FSW ... Otherwise, I have never experienced any problem at work and worship places (IDI, B, 35 years, 2021).

Discoursing of stigma, rejection and discrimination by the family and religious domain, the same participant stated,

Majority of parents become furious to children born feminine but pretend to act as men [presentation, clothes and haircuts] ... Some families reject and neglect such children, which adversely affects them physically, psychologically and morally ... Some of the neglected children run away from the families to live on the streets ... Some religious elders do not allow a femalelooking person wearing a trouser and a shirt or a T-shirt to enter the Church ... If you are lucky, they will give you a piece of cloth to wrap around the hips so as to look modesty to get into the worship place ... Some women and girls presenting in that fashion are sometimes summon you to the Church Leaders' Committee, where they would be prohibited from coming to that Church or punished at per the committee's discretion (IDI, F, 26 years, 2021).

Reporting on stigmatizationat work places, the same participant informed,

I am employed ... I conduct business online dealing with customers in Zambia, Zanzibar and Malawi ... My customers recognize, I am a man ... They never stigmatize me at all ... However, I have a friend, a transwoman, who worked for Vodacom Company ... The authorities terminated his employment contract when they knew he was a trans [transwoman] ... It is due to this reason that some of our colleagues with qualification never bother to apply for formal employment ... They are either self-employed or engage in sex work for their survival" (IDI, F, 26 years, 2021).

A Street Leader interviewed in Kinondoni reported, "I don't think anybody can stigmatize them [WSW] as we cannot prove that they engage in same sex behaviors and practices ... I have heard that unproperly dressed women are restricted entering worshiping places and government offices (IDI, K, 60 years, 2021). Another Street Leader interviewed in Kinondoni reported, "These women [WSW] are stigmatized because their sexual behaviors and practices are un-African, unwarranted in our society and illegal by constitution" (IDI, L, 32 years, 2021).

\subsection{Experiences with law enforcement machinery: the police}

We asked our participants on their (and their colleagues') experience with the law reinforcement machinery, the police in particular. A participant

\section{ISSN 2455-6378}

aged 46, never married, a mother of two children and sells sex to men, presented,

I have never heard of a case where the police harassed us [WSW] ... You know, there is no way the police would, beyond reasonable doubts, rule out that the two women sitting close to each other are lovers ... All I know, is that the police hunt and harass the MSM and female sex workers [FSWs] on the streets or in brothels... We [WSW] have sex with our partners at our homes, the partners' residences or lodges and guest houses ... It all depends on the couples' desired comfort, income, and status ... No police would follow us at such places (IDI, G, 46 years, 2021).

Reporting on experiences with the police, a participant aged 26, a transman and a university graduate, reported, "I have never had a problem with the police ... However, women dressed like men are restricted from accessing some government offices, the Immigration Offices, for example, where the guards send them back to get a piece of cloth [khanga or kitenge], failure of which, she will be denied services she needs" (IDI, F, 26 years, 2021).

\section{Discussion}

This formative qualitative study findings ascertain that - female same sex is a sexual behavior and practice considered foreign and "un-African" by the public, culturally unaccepted, not reorganized by the society and still illegal by the constitution. WSW are negatively perceived immoral by majority of the community members, and religious leaders. WSW are devalued, perceived to be ill-mannered and bad omen to the community. These findings are similar to results presented by Twenge, et al., [11] who found out that, although the number of same-sex sexual behavior is increasing among women than men, and is becoming more accepted now than in $90 \mathrm{~s}$, this increase is not reflected among the blacks and some religious groups in the United States of America (U. S. A).

WSW interviewed in this study reported facing almost all forms of violence: sexual, physical, psychological, and spiritual in varied combinations. Moreover, WSW like bisexual women, are known facing more higher rates of sexual violence than lesbians and straight women $[12,13]$ that make them more vulnerable although considered a "minority group". Their sex behaviors and practices being considered un-African, not culturally and legally accepted, have pushed many WSW to live in denial by majority of community members. However, to a small degree, WSW's existence is acknowledged and tolerated by a few of - their community members in 
different parts of the globe. This could be the reason why homosexuality is practiced in many African countries but rarely reported about [14].

\subsection{WSW stigma and discrimination}

WSW have faced stigma, discrimination and rejection [14]. At the family level, members immediately stigmatize any child when some same sex traits start to show and will try to change or to suppress some of the sexual behaviors or same sex features like dress code and haircuts. Due to fear of rejection, judgmental acts, stigma and discrimination, many WSW are not free and have failed to introduce their partners to family members. Also, some girls either allow following restrictions on dress code or facing the insults they get as tomboys from family members. The sense of insecurity leads WSW to lack self-confidence and have low self-esteem. A study conducted in South Africa [15] had similar observations, where WSW and lesbians reported experiencing lack of bonding with their families that reduced their sexual identity. Also, WSW revealed that, majority of landlords and landladies do force same sex tenants to evacuate their rented houses or rooms after finding out tenants exhibit same sex behaviors and practices. Some landlords and landladies either forcefully terminate rent agreements or halt WSW from using some shared spaces like toilets and cooking areas. This form of discrimination affects WSW's permanent settlement; forcing some of them to keep moving from one area to another looking for secure settlement. The lucky ones end up securing or renting houses in areas where their sex orientations are somehow tolerated. Worse situations, however, have been reported where WSW migrate from their countries of origin to seeks peace in foreign countries. The report by Romero shows that due to gender identity and orientation, LGBT face challenges in securing stable houses and many are left homeless [3].

Furthermore, our study participants reported denied their constitutional right to be elected (street) leaders due to their sexual orientation. This finding is ascertained by Gedro's [16] US study, where she reported lesbian leaders or representatives do face pressures like gender expression in their organizations. Moreover, WSW reported facing constant rejection in worship places mainly in churches, especially where worshipers are supposed to dress according to their sexes. This regulation has adversely affected the transmen and tomboys who feel discriminated by their religious leaders, and rejected by the society thus denied a right to worship. However, it was clear from observations and informal interviews with the gate keepers at some government offices (Immigration Headquarters, for

\section{ISSN 2455-6378}

example) and worshiping places that any woman or girl unproperly dressed (according the context in question) was denied access to the premises irrespective of her sexual orientation and other characteristics.

Certainly, the Tanzania Employment and Labor Relations Act, 2004, Sub Part C, prohibits discrimination of any form including sex and gender in the work place [17]. Unfortunately, WSW reported are not given equal opportunities and rights in the formal employment sector as their counterparts are. Some organizations and institutions were reported terminating jobs unknowingly offered to women engaging in same sex practices. This finding explains, in part, why majority of WSW with employment qualifications do not bother applying for positions in the formal sector and opt to work in the informal sector including sex work.

Constitutionally, WSW in this country have the right to access government services like fellow straight women and girls. However, this was reported not to be the case. Majority of our study participants reported experiencing discrimination by law enforcement bodies, the police in particular.The transmen,for example, reported (and were reported) denied access to services at Immigration Offices where they are required to put on feminine dresses to be allowed to enter the premises. In the transmen's, and other WSW's view, such acts humiliate their dignity and undermine their rights.

\subsection{WSW experience with rape}

Majority of the WSW we interviewed have ever experienced rape or heard about their colleagues being raped. This study demonstrated that rape as a sexual violence among WSW is a "double edged sword" experienced in three ways: (1) Straight men raping WSW especially tomboys and transmen with the intension of punishing them of their devilish sexual behaviors and practices, commonly referred to as "correct rape". The myth behind 'correction rape' is that women should have sex with men only. Hence, it is not an offense straight boys and men to (gang) rape WSW; (2) WSW raping straight girls with the goal to increase the number of WSW population. Majority of WSW believe that raping straight girls is another way of introducing them to same sex behaviors and practices [4]. In fact, many WSW testify developing same sex intimacy behavior after being raped by the WSW, and (3)Straight girls raping WSW with the reason that WSW can be used as demos for sex and because they (WSW) are regarded to be sluts whose libido is high all the time and often asking for sex [7]. This belief explains, in part, why majority (if not all) of the WSW report to have ever experienced molestation [4] and that 
sexual violence rates are so high among WSW compared to heterosexual women, happening in secrecy, and incidences are rarely reported [5].

\section{Conclusion and recommendations}

Many WSW have reported to have experienced different forms of violence in varied combinations [18]. However, our participants in this study reported sexual abuse and discrimination being the most experienced forms of violence. Violence is at every level of their lives and starts from family level. The consequences of violence on the individual's personal, social and economic development have been well studied and concluded to mostly affecting women and girls in the low socio-economic status (SES) groups [3, 19].

Discrimination and stigma have denied many WSW opportunities to actively participate in developmental activities starting from family decision making process to community leadership, majority are employment in the informal sector and face difficulties securing permanent residences. Those who strive hard to be employed in the formal or private sectors, face harsh working environment that force them to quit employment and engage in (health) risky behaviors and activities for survival. We recommend awareness creation through diversity training to (public) healthcare personnel at all levels as a strategy to improve WSW's quality care that would facilitate preventing and controlling illnesses among this at risk and expanding group in this country.

\section{Acknowledgements}

We would like to express our sincere gratitude to the participants who willingly shared their experiences and research assistants who conducted interviews and focus group discussions. Also, to SIDA small grants scheme ant MUHAS for providing funds that made this study possible.

\section{References}

[1] Knight, D. and Jarret, D. Preventive Health Care for Women Who Have Sex with Women. Am Fam Physician. 95(5):314-321.(2017). Available at:

https://www.aafp/2017/0301/p314.pdfAccessed on January 27, 2021.

[2] The Williams Institute, U. S. of L. Same-sex Couple Data \& Demographics - The Williams Institute.(2019). Available at: https://williamsinstitute.law.ucla.edu/visualizati on/lgbt-
ISSN 2455-6378

stats/?topic $=$ SS\&characteristic $=$ female\#density Accessed on 23 March 2021.

[3] Romero, A. P., Goldberg, S. K., \& Vasquez, L. A. Research that matters LGBT people and housing affordability and homelessness (Issue April).(2020). Available at: http://williamsinstitute.law.ucla.edu/wpcontent/uploads/LGBT-Housing-Apr-2020.pdf Accessed on May 8, 2021.

[4] Girshick, L. B. Woman-to-Woman Sexual Violence: Does She Call It Rape? -- Google Books. (n.d.). Available at: https://books.google.co.tz/books?hl=en\&lr=\&id $=\mathrm{nHg} 40 \mathrm{DDZWj}$ AC\&oi=fnd \&pg=PP1\&dq=sexu al+violence+among+lesbians\&ots=IPdUwOYM KZ\&sig=WwukgesnEvAoOFclkBepY5YMRIM $\&$ redir_esc $=\mathrm{y} \# \mathrm{v}=$ onepage $\& \mathrm{q}=$ sexual violence among lesbians\&f=false Accessed on April 12, 2021.

[5] Center for Diseace Control and Preventios. (CDC). The National Intimate Partner and Sexual Violence Survey 2010 Findings on Victimization by Sexual Orientation. In National Intimate. (2010).Available at: https://doi.org/10.1037/e541522013-001

Accesses on April 27, 2021.

[6]Wikipedia. Marriage in South Africa.(2014). Available at: https://en.wikipedia.org/wiki/Samesex_marriage_in_South_Africa Accessed on April 25, 2021.

[7] Turley, M. South Africa: The Fight for Acceptance in the Rainbow Nation | Pulitzer Center. Pulitzer Center.(2012). Available at: https://pulitzercenter.org/stories/south-africafight-acceptance-rainbow-nation Accessed on May 9, 2021.

[8] Human Rights Watch/PEMA Kenya (2015). The Issue is Violence. Attacks on LBGT People on Kenya's Coast.(2015). Available at: https://www.hrw.org/report/2015/09/28/issueviolence/attacks-lgbt-people-kenyas-coast Accessed on February 15, 2021.

[9] Ouma, J. W. The Real Situation of Lesbian, Gay, Bisexual and Transgender Individuals and Activists in Tanzania. LGBT Voice Tanzania. (2014).Available at: https://lgbtvoicetz.org/thereal-situation-of-lesbian-gay-bisexual-andtransgender-individuals-and-activists-intanzania/ Accessed on February 18, 2021. 
[10] British Broadcasting Coorpration. (BBC). Tanzania: Anti-gay crackdown in Dar es Salaam. (2018).Available at: https://www.bbc.com/news/world-africa46048804 Accesses on April 27, 2021.

[11] Twenge, J. M., Sherman, R. A., \& Wells, B. E. Changes in American Adults' Reported SameSex Sexual Experiences and Attitudes, 19732014. Archives of Sexual Behavior. 45(7):17131730. (2016).Available at: https://doi.org/10.1007/s10508-016-0769-4 Accessed on April 16, 2021.

[12] Johnson, N. L., \& Grove, M. B. Why Us? Toward an Understanding of Bisexual Women's Vulnerability for and Negative Consequences of Sexual Violence. Journal of Bisexuality, 17(4):435-450. (2017). Available at: https://doi.org/10.1080/15299716.2017.1364201 Accessed on May 17, 2021.

[13] Schoentjes, S. the Evolution of Abusive Requirements for Gender Recognition in the Council of Europe 'S Most Progressive. 20182019. (2019).Available at: https://lib.ugent.be/catalog/rug01:002782645 Accessed on: March 282021.

[14] Izugbara, C., Bakare, S., Sebany, M., Ushie, B., Wekesah, F., and Njagi, J. Regional legal and policy instruments for addressing LGBT exclusion in Africa. In Sexual and Reproductive Health Matters. 28(1):1-14. (2020). Available at:

https://doi.org/10.1080/26410397.2019.1698905 Accessed on May 17, 2021.

[15] Romijnders, K. A., Wilkerson, J. M., Crutzen, R., Kok, G., Bauldry, J., and Lawler, S. M. Strengthening Social Ties to Increase

\section{ISSN 2455-6378}

Confidence and Self-Esteem Among Sexual and Gender Minority Youth. Health Promotion Practice.18(3):341-347. (2017). Available at: https://doi.org/10.1177/1524839917690335 Accessed on April 27, 2021.

[16] Gedro, J. The Lavender Ceiling Atop the Global Closet: Human Resource Development and Lesbian Expatriates. Human Resource Development Review. 9(4):485-404. (2010).Available at: https://journals.sagepub.com/doi/pdf/10.1177/15 34484310380242?casa token=ir6MfTmIH0sAA AAA:fKYCKg5iTNyBnr3QwItcLPddVNSvMf KZ-yPj5SbIf5KDKLJyHD90XJGzD78tJL59iLN5NrlSGRAATM

Accessed on May 13, 2021.

[17] United Republic of Tanzania/Ministry of Labor. Employment and labour relations act, 2004 arrangement of sections. In Elra (pp. 184).(2004). Available at: http://www.kazi.go.tz/uploads/documents/en/14 37999724-Employment and Labour Relations Act 6-2004.pdf at 23.10.2015 Accessed on April 12, 2021.

[18] Vetten, L. Rape and other forms of sexual violence in South Africa. ISS Policy Brief. 72:17.(2014). Available http://www.ci.uct.ac.za/sexualviolence/briefs/rape-and-other-forms-of-sexualviolence-in-SA. Accessed on May 19, 2021.

[19] de Vos, P. (2007). The 'Inevitability' of SameSex Marriage in South Africa's Post-Apartheid State. South African Journal on Human Rights, 23(3): 432-465. Available at: https://doi.org/10.1080/19962126.2007.1186493 1 Accessed on May 15, 2021. 